\title{
In situ recordings of presumed folliculo-stellate cells in the intermediate lobe of the pituitary gland of Xenopus laevis
}

\author{
J.G.G. Borsta, , J.C. Loddera, E.W. Roubos ${ }^{\mathrm{b}}$, K.S. Kits ${ }^{\mathrm{a}, *}$ \\ ${ }^{a}$ Research Institute of Neurosciences, Section of Membrane Physiology, Faculteit Biologie, Vrije Universiteit, De Boelelaan 1087, \\ 1081 HV Amsterdam. The Netherlands \\ ${ }^{b}$ Department of Cellular Animal Physiology, Subfaculty of Biology, University of Nijmegen, Tournooiveld 1, 6525 ED Nijmegen, The Netherlands
}

Received 19 September 1995; revised version received 18 March 1996; accepted 2 April 1996

\begin{abstract}
In situ whole cell voltage clamp recordings of presumed folliculo-stellate cells were made in the intermediate lobe of the clawed toad Xenopus laevis. Lucifer Yellow fillings revealed, in addition to the small, spherical melanotropes, a population of larger cells with many processes that were, to a limited extent, dye-coupled and are assumed to be folliculo-stellate cells. The presumed folliculo-stellate cells differed strongly from the melanotropes in electrophysiological properties. The cells had a membrane resistance of $<600 \mathrm{M} \Omega$ (at 100 to $-80 \mathrm{mV}$ ) and a membrane potential of ca. $-90 \mathrm{mV}$, close to the equilibrium potential for $\mathrm{K}^{+}$. At potentials of $\geq-20 \mathrm{mV}$, most of the cells displayed a rapidly activating and slowly inactivating outward $\mathrm{K}^{+}$current. In all cells, hyperpolarizing pulses to $\leq-100 \mathrm{mV}$ activated an inward rectifying $\mathrm{K}^{+}$current.
\end{abstract}

Keywords: In situ recordings; Inward rectifier; $\mathrm{K}^{+}$current; Glial cells; Folliculo-stellate cells; Intermediate lobe; Xenopus laevis

The intermediate lobe of the pituitary gland of Xenopus laevis contains a homogeneous population of endocrine cells, the melanotropes, and a population of glia-like cells, the folliculo-stellate cells (FSCs) [7,8]. The melanotropes produce $\alpha$-melanophore-stimulating hormone (MSH) that, in amphibians, regulates skin colour $[7,8]$. When the animal is placed on a dark background, $\alpha$-MSH is released into the blood and binds to the melanophores in the skin, thereby stimulating dispersion of pigment in these cells and generating a dark skin colour. The function of the other cell type in the intermediate lobe, the FSCs, is unclear [8]. FSCs in the pituitary are considered as equivalent to glial cells in the nervous system. To study glial cells in their natural environment, the in situ patch clamp technique has been applied to glial cells in slice preparations $[2,10,13,15]$ and isolated sympathetic ganglia [4]. Also, micro-electrode recordings of stellate cells in the pars intermedia of the rat were reported [11]. We performed whole cell current clamp and

\footnotetext{
* Corresponding author. Tel.: +31 20 4447096; fax: +31 20 4447123; e-mail: ksk@bio.vu.nl.

${ }^{1}$ Present address: Abteilurg Zellfysiologie, Max Planck Institut für medizinische Forschung, Jahnstrasse 29, 69120 Heidelberg, Germany.
}

voltage clamp recordings of presumed FSCs in situ in the isolated but intact intermediate lobe of the clawed toad Xenopus laevis, to characterize their electrical properties.

The neurointermediate lobe of the pituitary gland was dissected from laboratory bred adult Xenopus laevis [3]. Whole-cell voltage clamp and current clamp recordings were made as described previously [3]. Whole-cell capacitance was estimated with the aid of the capacitance compensation on the EPC-7 patch clamp amplifier (List, Germany). Series resistance was $\leq 15 \mathrm{M} \Omega$ and compensated by about $70 \%$. Maximal voltage errors without compensation were $7 \mathrm{mV}$. Data from short $(<250 \mathrm{~ms})$ voltage steps were sampled at $9 \mathrm{kHz}$ and filtered at $3 \mathrm{kHz}$, data from $1 \mathrm{~s}$ steps were sampled at $1 \mathrm{kHz}$ and filtered at $300 \mathrm{~Hz}$. Input resistances were determined from the average response to 20 hyperpolarizing pulses of $20 \mathrm{mV}$.

The recording chamber (bath volume approximately $0.4 \mathrm{ml}$ ) was continuously perfused at approximately $3 \mathrm{ml} /$ min with standard extracellular solution, consisting of (in $\mathrm{mM}$ ): $90 \mathrm{NaCl}, 2 \mathrm{KCl}, 2 \mathrm{CaCl}_{2}, 2 \mathrm{MgCl}_{2}, 10 \mathrm{D}$-glucose and $26 \mathrm{NaHCO}_{3}(\mathrm{pH}$ kept at 7.4 by bubbling with carbogen $\left.\left(95 \% \mathrm{O}_{2}, 5 \% \mathrm{CO}_{2}\right)\right)$. In some experiments 5$20 \mu \mathrm{M}$ bicuculline methiodide (Sigma, USA) was added to the extracellular saline to block GABAergic inputs [3]. 
The standard pipette solution contained (in $\mathrm{mM}$ ): 100 $\mathrm{KCl}, 2 \mathrm{MgATP}, 2 \mathrm{CaCl}_{2}, 10$ EGTA and $10 \mathrm{HEPES}(\mathrm{pH}$ 7.4 set with $\mathrm{KOH}$ ). In some experiments $\mathrm{KCl}$ was replaced by $\mathrm{CsCl}$ or $\mathrm{K}$-aspartate.

To perform dye fillings, patch electrodes were filled with 0.1 or $0.5 \%$ Lucifer Yellow (LY; lithium salt; Sigma, St. Louis, USA) solution in standard saline. LY was injected for 1-10 min with repetitive hyperpolarizing pulses of 2-3 nA. The duration of filling was usually determined by the lifetime of the recording. In most experiments, the intermediate lobes were fixed with phosphate-buffered $5 \%$ dextrose, $5 \%$ formaldehyde solution and cleared with dimethyl sulfoxide [5].

Identification of the recorded cells was based on correlating the electrophysiological characteristics of the cells with their morphology as determined in a number of LY fillings. Lucifer Yellow fillings were performed in seven recordings of presumed melanotropes and 22 recordings of presumed FSCs. The melanotropes appeared as small, spherical cells $(5-10 \mu \mathrm{m})$ without any processes. Putative FSCs, on the other hand, were larger $(\sim 10 \mu \mathrm{m})$, they had a fibroblast- or astrocyte-like appearance with various protrusions and, in five cases, they displayed dye coupling with one or at most two other FSCs. These differences in morphology correlated with different electrophysiological properties. In short, melanotropes had a high membrane resistance $(\geq 5 \mathrm{G} \Omega)$ and a small capacitance of $7.9 \pm$ $0.6 \mathrm{pF}(n=32)$. The capacitive transient was well described by a single exponential function, suggesting that the melanotropes are electrotonically compact. The membrane potential was $-44.0 \pm 0.8 \mathrm{mV}(n=27)$ and almost all cells fired action potentials in the cell attached configuration (voltage clamp mode) prior to whole cell re- cording, as well as in the whole cell configuration (current clamp mode). The melanotropes received spontaneous GABAergic inputs. In contrast, putative FSCs had a much more negative membrane potential $(-89.9 \pm$ $0.9 \mathrm{mV}$, i.e. close to the $E_{\mathrm{K}} ; n=26$ ). Their membrane resistance was much less than that of the melanotropes and depended on the membrane potential, being $232 \pm$ $90 \mathrm{M} \Omega(n=13)$ between -80 and $-100 \mathrm{mV}$ versus $615 \pm$ $253 \mathrm{M} \Omega(n=11)$ at $-40 \mathrm{mV}$ holding potential. The capacitive transient of these cells was not well described by a single exponential function. Unlike the melanotropes, they did not fire action potentials and they did not receive spontaneous inputs. The differences in electrophysiological characteristics of the two cell types made it easy to distinguish them during in situ recording.

Presumed FSCs under voltage clamp revealed nonlinear responses to both depolarizing and hyperpolarizing command steps. For this reason, the current responses were not corrected for leakage. Their lower membrane resistance at more hyperpolarized potentials suggests that voltage-dependent channels contribute to the membrane conductance at these potentials. To test this, $1 \mathrm{~s}$ step pulses from a holding of $-40 \mathrm{mV}$ to command voltages ranging from -60 to $-140 \mathrm{mV}$ were given. The responses consisted of two components. At potentials of $>-100 \mathrm{mV}$ an instantaneous current response was observed, that slowly decayed. Hyperpolarizing steps to potentials of $\leq-100 \mathrm{mV}$ yielded, in addition to the instantaneous component, a slowly activating inward current in all cells tested ( $n=19$; Fig. 1A). The amplitude of the slowly activating inward current varied strongly between cells. Large and very slow tail currents occurred upon stepping back to $-40 \mathrm{mV}$ (Fig. 1A). When a holding potential of
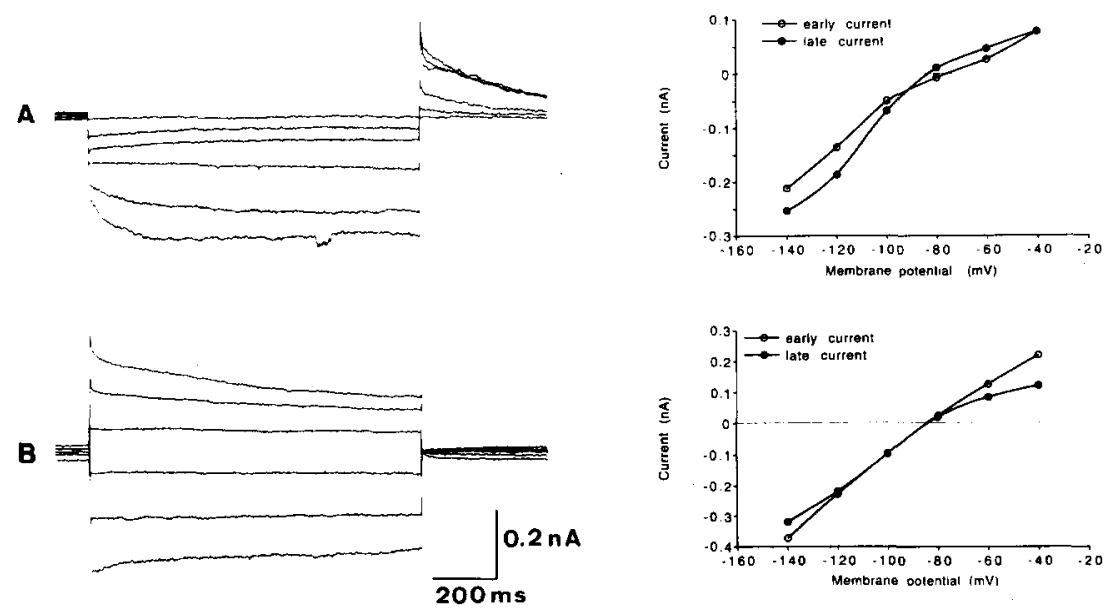

Fig. 1. Inward rectifying currents in presumed folliculo-stellate cells in situ in the intermediate lobe. (A) Voltage steps from -40 to $-140 \mathrm{mV}$, standard non-selective internal and external salines. Holding potential $-40 \mathrm{mV}$. Left panel: current responses increasing alinearly with increasing voltage. Traces at $\leq-100 \mathrm{mV}$ show a slowly activating current that does not decay during the voltage step. Note the slow tail currents. Right panel: $I / V$ relationships of the early and late current, measured at $t=100 \mathrm{~ms}$ and $t=800 \mathrm{~ms}$, respectively. (B) Left and right panels: like (A), but using a holding potential of $-90 \mathrm{mV}$. Recordings taken from same cell as in (A). Note that at all test potentials current responses are instantaneous and that tail currents are almost completely lacking. $I N$ relationships at $t=100 \mathrm{~ms}$ and $t=800 \mathrm{~ms}$. 
$-90 \mathrm{mV}$ was applied, the slowly activating current response upon steps to $\leq-100 \mathrm{mV}$ was strongly reduced or no longer observed and the traces were dominated by the instantaneous, slowly decaying current response. These responses reversed around $-90 \mathrm{mV}$. In the outward direction, the currents were smaller than inwardly. This was especially clear for the late currents as the outward responses inactivated more strongly than the inward currents (Fig. 1B). Tail currents were not seen upon stepping back to $-90 \mathrm{mV}$, the $\mathrm{K}^{+}$equilibrium potential (Fig. 1B). This means that, most likely, both the slowly activating current and the instantaneous current are carried by $\mathrm{K}^{+}$ ions. The absence of tail currents at $-90 \mathrm{mV}$ also implies that (at $-40 \mathrm{mV}$ ) they clid not result from a bad voltage clamp.

Outward currents were elicited by depolarizing steps from $-80 \mathrm{mV}$ to potentials of $\geq-40 \mathrm{mV}$. In two out of 11 cells only an instantaneous response with an ohmic behaviour was observed, yielding a linear current-voltage relationship. In these responses a clear rising phase, distinct of the capacitive transient, appeared to be lacking (Fig. 2A). To test the passive nature of these responses, the response to the voltage step from -80 to $-40 \mathrm{mV}$ was, after linear scaling, subtracted from the experimental responses. This confirmed that at all potentials these responses were ohmic and not voltage-dependent (Fig. 2A). Between the cells, the decay of this response varied from
20 to $40 \%$ in $100 \mathrm{~ms}$. Extrapolation of the linear $I / \mathrm{Vs}$ yielded a reversal potential of about $-85 \mathrm{mV}$. In addition, with a holding potential of $-80 \mathrm{mV}$ no clear tail currents were seen. These observations reinforce the conclusion that the instantaneous, voltage-independent currents are carried by $\mathrm{K}^{+}$ions.

In nine of the 11 cells a voltage-dependent outward response was observed at potentials of $-20 \mathrm{mV}$ and above, superimposed on the instantaneous, ohmic response. The outward response could be isolated by subtraction of the purely passive response obtained at $-40 \mathrm{mV}$, after linear scaling of this response to the appropriate voltage (Fig. 2B). The outward current activated rapidly and the amplitude was voltage-dependent. This current largely inactivated during the $100 \mathrm{~ms}$ testpulse (Fig. 2B). In two other recordings with $\mathrm{Cs}^{+}$instead of $\mathrm{K}^{+}$in the pipette saline, voltage-dependent outward currents were not observed.

The electrophysiological properties of the presumed FSCs, i.e. a low membrane potential $(\sim-90 \mathrm{mV})$, a low membrane resistance and the presence of potassium currents, as well as the dye coupling with other FSCs, underline their relationship with glia in the central nervous system [9].

FSCs in the rat intermediate lobe recorded with sharp microelectrodes [11] had a much smaller membrane resistance $(<50 \mathrm{M} \Omega)$ and a less negative resting potential than the putative FSCs in Xenopus. Furthermore, in FSCs of
A
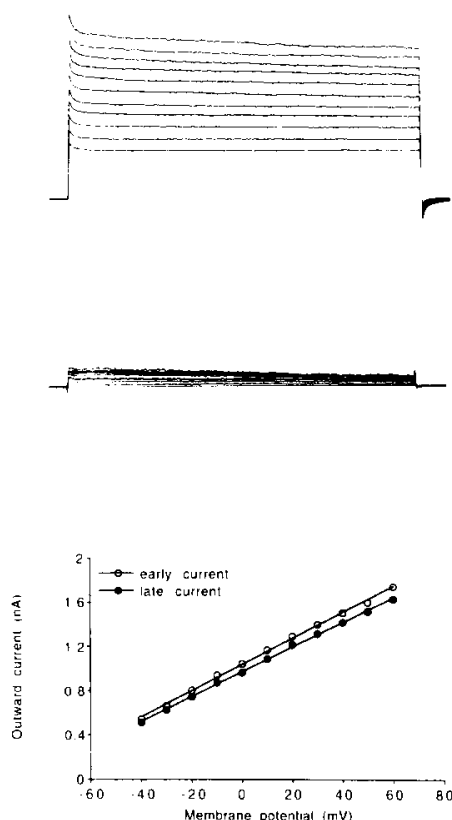
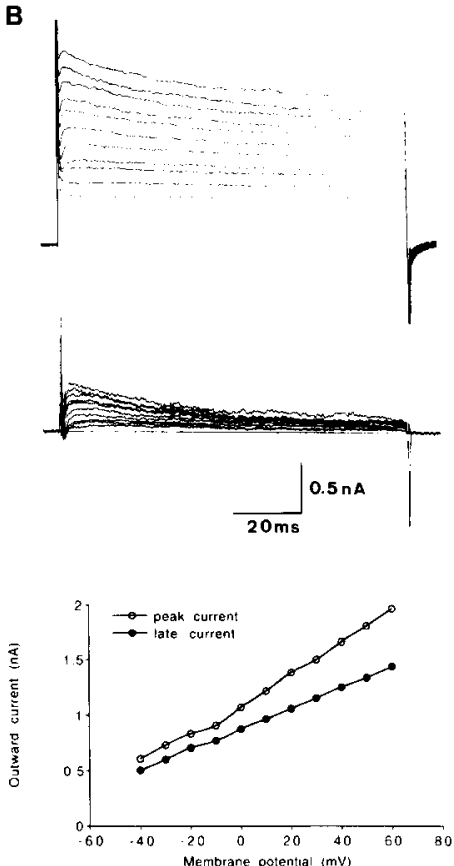

Fig. 2. Outward currents in presumed folliculo-stellate cells in situ in the intermediate lobe. Voltage steps ranged from -40 to $+60 \mathrm{mV}$; holding potential $-80 \mathrm{mV}$; standard salines. (A) Upper panel: family of current traces of a cell lacking clearly active responses. Note, however, the decay in the current traces. Middle panel: currents remaining after subtraction of the response at $-40 \mathrm{mV}$ scaled to the appropriate voltage. Lower panel: $I N$ curves taken at $t=5 \mathrm{~ms}$ (early currert) and $t=100 \mathrm{~ms}$ (late current). (B) Current traces before (upper panel) and after (middle panel) subtraction of the scaled passive response at $-40 \mathrm{mV}$ and $I / V$ relations (lower panel; peak outward current and late current at $t=100 \mathrm{~ms}$ ) of a cell showing active responses to depolarizing steps. Note the rising phase of the current at $\geq-20 \mathrm{mV}$ 
the rat no voltage-dependent conductances were detected [11]. Presumably these species differences are explained by the much more extensive coupling between FSCs observed in the rat [11], that would make it difficult to obtain good voltage clamp and low noise recording, so that small voltage-dependent currents as described in this study may have gone undetected. Other factors, such as the higher shunt resistance of microelectrodes as compared to patch electrodes, may have contributed to the observed differences.

The presumed FSCs had a low membrane potential (around $-90 \mathrm{mV}$, close to the $\mathrm{K}^{+}$equilibrium potential) and a low membrane resistance at the resting membrane potential, suggesting a large $\mathrm{K}^{+}$permeability at rest. The membrane resistance was voltage-dependent, increasing at more depolarized potentials. Hyperpolarization from depolarized membrane potentials evoked a slowly activating inward current. Hyperpolarizing steps from a holding potential of $-90 \mathrm{mV}$ induced only little additional slowly activating inward current, suggesting that at $-90 \mathrm{mV}$ the current is almost fully activated. From these properties it seems justified to label this current as an inwardly rectifying $\mathrm{K}^{+}$current. This current inactivates slowly at potentials $\geq-80 \mathrm{mV}$. Accordingly, slow tail currents were seen at $-40 \mathrm{mV}$. The large size and the slow time courses of the tail currents (Fig. 1A) and the ohmic nature of the early responses to depolarizing or hyperpolarizing steps (Fig. 1B) suggest that the inward rectification mainly results from inactivation at more depolarized potentials.

The important role of inward rectifying $\mathrm{K}^{+}$channels for the resting membrane conductance was hypothesized to be a general characteristic of glial cells [1] and recently, for instance, substantiated in cultured cerebellar oligodendrocytes [6] and spinal cord astrocytes [12], as well as in satellite cells recorded in situ in sympathetic ganglia [4]. In satellite cells, the inward rectifying properties were only observed in the presence of elevated concentrations of extracellular $\mathrm{K}^{+}$. Also, in astrocytes the inward rectifying conductance was enhanced with high outside $\mathrm{K}^{+}$. It is thus very well possible that in FSCs too, inward rectification will be more prominent with higher extracellular $\mathrm{K}^{+}$concentrations.

In addition to the inward rectifier current found in all putative FSCs, most of the cells displayed a voltagedependent, outward $\mathrm{K}^{+}$current, that may have a function in membrane repolarization. A similar current was observed in astrocytes in the hippocampus [13]. In a minority of $<20 \%$ of the cells this type of $\mathrm{K}^{+}$current was lacking.

We did not look for voltage-activated $\mathrm{Na}^{+}$or $\mathrm{Ca}^{2+}$ currents. However, Fig. 2B indicates that small inward currents may be present. Very large $g_{\mathrm{K}} / g_{\mathrm{Na}}$ ratios are normal for glial cells $[13,14]$.

The electrophysiological properties of the presumed FSCs and the coupling between them suggest their primary function to be the classical glial function, i.e. buffer- ing or regulating local $\mathrm{K}^{+}$concentrations, with the inward rectifier and outward $\mathrm{K}^{+}$current providing uptake and release pathways, respectively, for $\mathrm{K}^{+}$ions, and gap junctions providing a means to increase their potential for spatial buffering.

We thank Dr. T.A. de Vlieger and Dr. A.B. Brussaard for comments on the manuscript. J.G.G.B was supported by grant number 426.903-P from the Netherlands Organization for the Advancement of Pure Research (NWO).

[1] Barres, B.A., New roles for glia, J. Neurosci., 11 (1991) 36853694.

[2] Berger, T., Schnitzer, J. and Kettenmann, H., Developmental changes in the membrane current pattern: $\mathrm{K}^{+}$buffer capacity and morphology of glial cells in the corpus callosum slice, J. Neurosci., 11 (1991) 3008-3024.

[3] Borst, J.G.G., Lodder, J.C. and Kits, K.S., Large amplitude variability of GABAergic IPSCs in melanotropes from Xenopus laevis: evidence that quantal size differs between synapses, J. Neurophysiol., 71 (1994) 639-655.

[4] Gola, M., Niel, J.P., Delmas, P. and Jacquet, G., Satellite glial cells in situ within mammalian prevertebral ganglia express $\mathrm{K}^{+}$ channels active at rest potential, J. Membr. Biol., 136 (1993) 7584.

[5] Grace, A.A. and Llínas, R., Morphological artifacts induced in intracellularly stained neurons by dehydration: circumvention using rapid dimethyl sulfoxide clearing, Neuroscience, 16 (1985) $461-475$.

[6] Gaillard, S. and Bossu, J.L., Voltage-gated ionic currents in mature oligodendrocytes isolated from rat cerebellum, Neurosci. Lett., 190 (1995) 191-194.

[7] Jenks, B.G., Verburg-van Kemenade, B.M.L. and Martens, G.J.M., Pro-opiomelanocortin in the amphibian pars intermedia: a neuroendocrine model system. In M.E. Hadley (Ed.), The Melanotropic Peptides, Vol. 1, CRC Press, Boca Raton, FL, USA, 1988, pp. 103-126.

[8] Jenks, B.G., Leenders, H.J., Martens, G.J.M. and Roubos, E.W., Adaptation physiology: the functioning of pituitary melanotrope cells during background adaptation of the amphibian Xenopus laevis, Zool. Sci., 10 (1993) 1-11.

[9] Kuffler, S.W., Neuroglial cells: physiological properties and a potassium mediated effect of neuronal activity on the glial membrane potential, Proc. R. Soc. Lond. Ser. B, 168 (1967) 1-21.

[10] Marrero, H., Orkand, P.M., Kettenmann, H. and Orkand, R.K., Single channel recording from glial cells on the untreated surface of the frog optic nerve, Eur. J. Neurosci., 3 (1991) 813-819.

[11] Mudrick-Donnan, L.A., Williams, P.J., Pittman, Q.J. and MacVicar, B.A., Postsynaptic potentials mediated by GABA and dopamine evoked in stellate glial cells of the pituitary pars intermedia, J. Neurosci., 13 (1993) 4660-4668.

[12] Ransom, C.B. and Sontheimer, H., Biophysical and pharmacological characterization of inwardly rectifying $\mathrm{K}^{+}$currents in rat spinal cord astrocytes, J. Neurophysiol., 73 (1995) 333-346.

[13] Sontheimer, H. and Waxman, S.G., Expression of voltage-gated ion channels by astrocytes and oligodendrocytes in the hippocampal slice, J. Neurophysiol., 70 (1993) 1863-1873.

[14] Steinhauser, C., Kressin, K., Kuprijanova, E., Weber, M. and Seifert, G., Properties of voltage-activated $\mathrm{Na}^{+}$and $\mathrm{K}^{+}$currents in mouse hippocampal glial cells in situ and after acute isolation from tissue slices, Pflugers Arch. Eur. J. Physiol., 428 (1994) $610-620$.

[15] Steinhauser, C., Berger, T., Frotscher, M. and Kettenmann, H., Heterogeneity in the membrane current pattern of identified glial cells in the hippocampal slice, Eur. J. Neurosci., 4 (1992) 472 484. 